Ge, H., Vasandani, V., Huff, J.K., Audus, K.L., Himes, R.H., Seelig, A., and Georg, G.I. (2006) Synthesis and interactions of 7-deoxy-, 10deacetoxy and 7,10-dideoxypaclitaxel with MCF7-ADR cancer cells and bovine brain microvessel endothelial cells. Bioorg. Med. Chem. Lett., 16, 433-436. PMID: 16271474. Publisher's official version: <http://dx.doi.org/10.1016/j.bmcl.2005.09.043>. Open Access version: http://kuscholarworks.ku.edu/dspace/.

[This document contains the author's accepted manuscript. For the publisher's version, see the link in the header of this document.]

Paper citation: Ge, H., Vasandani, V., Huff, J.K., Audus, K.L., Himes, R.H., Seelig, A., and Georg, G.I. (2006) Synthesis and interactions of 7-deoxy-, 10-deacetoxy and 7,10-dideoxypaclitaxel with MCF7-ADR cancer cells and bovine brain microvessel endothelial cells. Bioorg. Med. Chem. Lett., 16, 433-436. PMID: 16271474

Abstract: see below

Text of paper:

\title{
Synthesis and Interactions of 7-Deoxy-, 10-Deacetoxy, and 10-Deacetoxy-7-Deoxypaclitaxel with NCI/ADR-RES Cancer Cells and Bovine Brain Microvessel Endothelial Cells
}

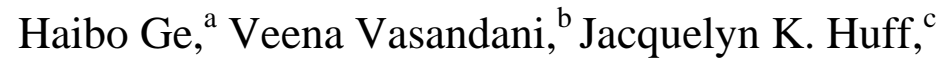 \\ Kenneth L. Audus, ${ }^{\mathrm{b}}$ Richard H. Himes, ${ }^{\mathrm{c}}$ Anna Seelig, ${ }^{\mathrm{d}}$ and Gunda I. Georg ${ }^{\mathrm{a} *}$ \\ ${ }^{a}$ Department of Medicinal Chemistry, ${ }^{b}$ Department of Pharmaceutical Chemistry, ${ }^{c}$ Department of Molecular Biosciences, \\ 1251 Wescoe Hall Drive, ${ }^{a}$ University of Kansas, Lawrence, KS 66045-7582, USA \\ ${ }^{d}$ Department of Biophysical Chemistry, Biocenter of the University of Basel, \\ Klingelbergstrasse 70, 4056 Basel, Switzerland
}

This is where the receipt/accepted dates will go; Received Month XX, 2005; Accepted Month XX, 2005 [BMCL RECEIPT]

\begin{abstract}
Deoxypaclitaxel, 10-deacetoxypaclitaxel and 10-deacetoxy-7-deoxypaclitaxel were prepared and evaluated for their ability to promote assembly of tubulin into microtubules, their cytotoxicity against NCI/ADR-RES cells and for their interactions with Pglycoprotein in bovine brain microvessel endothelial cells. The three compounds were essentially equivalent to paclitaxel in cytotoxicity against NCI/ADR-RES cells. They also appeared to interact with P-glycoprotein in the endothelial cells with the two 10-deacetoxy compounds having less interaction than paclitaxel and 7-deoxypaclitaxel. C 2000 Elsevier Science Ltd. All rights reserved.
\end{abstract}

Paclitaxel (1, Fig. 1), a cytotoxic agent from the bark of the Pacific yew (Taxus brevifolia), ${ }^{1}$ exerts its activity by altering tubulin dynamics. ${ }^{2}$ Paclitaxel, as well as its semisynthetic analogue docetaxel (2, Fig. 1), are effective agents for the treatment of ovarian and breast cancer, Kaposi's sarcoma, and non-small cell lung cancer. ${ }^{3}$ However, the continued evaluation of new analogues is important, because drug resistance has developed, and paclitaxel, like many other anticancer agents, does not cross the blood-brain barrier (BBB). Active efflux by Pglycoprotein (Pgp) is believed to be responsible for the lack of brain uptake of many anticancer drugs, leaving brain cancer patients with few viable treatment options. ${ }^{4,5}$ Paclitaxel's limited oral bioavailability, lack of accumulation in brain tissues, and efficacy in brain tumors has been attributed to active efflux by Pgp. ${ }^{6,7}$ In our efforts to develop paclitaxel analogues that can cross the $\mathrm{BBB}^{8}$ we are studying the influence of chemical modifications of paclitaxel on Pgp in the BBB and are now reporting new results concerning structure-efflux relationships of paclitaxel analogues.

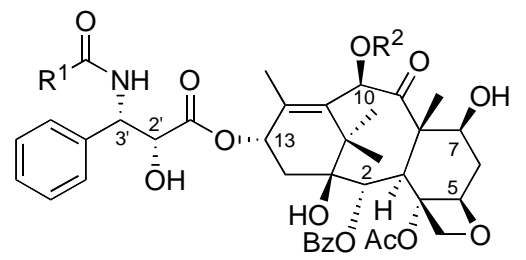

Figure 1. Structures of paclitaxel $\left(1, \mathrm{R}^{1}=\mathrm{Ph}, \mathrm{R}^{2}=\mathrm{Ac}\right)$ and docetaxel $(2$, $\mathrm{R}^{1}=\mathrm{O}$-tert-Bu, $\mathrm{R}^{2}=\mathrm{H}$ ). 
A comparison of the structural features of over one hundred known substrates and modulators for Pgp suggested that clusters of hydrogen bond acceptors (electron donating groups), arranged in fixed spatial distances from each other, are required for recognition by Pgp binding sites. ${ }^{9-11}$ The recognition elements are formed either by two or by three electron donating groups. It was also hypothesized that the number and strength of the hydrogen bonds present in a molecule determine Pgp affinity. This implies that one could remove recognition elements from the molecule that are not necessary for biological activity and improve activity against multi-drug resistant cancers and achieve BBB penetration.

We analyzed paclitaxel for Pgp recognition patterns and determined six relevant hydrogen bond acceptor groups (Fig. 2). Groups 1-4 (Fig. 2) are so-called type I units that are formed by two hydrogen bond acceptor groups (A or a) with a spatial separation of $2.5 \pm 0.3 \AA$. Strong electron donating groups, containing oxygens are denoted as " $\mathrm{A}$ " and less potent donors such as tertiary amines, halides, sulfides or $\pi$-electron donating groups as "a”. In addition, two so-called type II units, groups $\mathbf{5}$ and $\mathbf{6}$, were identified. Type II units are formed either by two hydrogen bond acceptor groups with a spatial separation of $4.6 \pm 0.6 \AA$ (group 5: AA (1.5) pattern between the 7-hydroxyl and the 5-ether group of the oxetane moiety) or by three hydrogen bond acceptor groups separated from each other by $2.5 \pm$ $0.3 \mathrm{~A}$, with the outer two acceptor groups at a distance of $4.6 \pm 0.6$ A (group 6: AAA (1.4.6) relationship between the $\mathrm{C} 9$ carbonyl and the $\mathrm{C} 10$ acetate). The type I units are found in all Pgp substrates and type II units are present in all Pgp inducers and many Pgp substrates.

According to structure-activity relationship studies, neither the C7 hydroxy group nor the C10 acetyl group are essential for bioactivity. ${ }^{12}$ Substitution at C7 and C10 is well tolerated, ${ }^{12}$ and it has been demonstrated that these regions of the molecule are important for Pgp affinity. ${ }^{13}$ Ojima and collaborators have shown that specific modifications at the $\mathrm{C} 10$ position (i. e. propionate instead of acetate at O10) of 3'-dephenyl-3'-isobutylpaclitaxel and related analogues resulted in a significant increase in cytotoxicity, especially against NCI/ADR-RES cells, expressing the MDR (multi-drug resistant) phenotype. This result was ascribed to an effective inhibition of binding to Pgp by these analogues. ${ }^{13}$ The effects are complex, however, and replacement of the 10 -acetate with a 10-propionate group in paclitaxel does not lead to an increase in cytotoxicity against MDR-expressing cancer cells. $^{14}$ In another example, we have recently shown that Tx-67, a paclitaxel analogue, carrying a 10-O-succinyl monoester moiety, is able to evade Pgp-mediated efflux and can permeate the BBB in vitro and in situ. ${ }^{8}$ Of interest in this context are also recent reports, disclosing that TXD258 (7-O-methyl-10-O-methyldocetaxel) is able to cross the BBB, and that RPR-109881A (a 7,8-cyclopropyl docetaxel analogue) is effective against MDR-positive and taxane resistant human tumor xenografts. ${ }^{15}$

Based on these previous observations, we decided to explore additional chemical modifications of the putative group 5 and $\mathbf{6}$ paclitaxel recognition elements with the goal to decrease the strength for Pgp binding and thereby improve activity against MDR cancer cells and enhance BBB permeation. We therefore prepared and evaluated paclitaxel analogues lacking the C7 hydroxy group and/or C10 acetoxy groups.

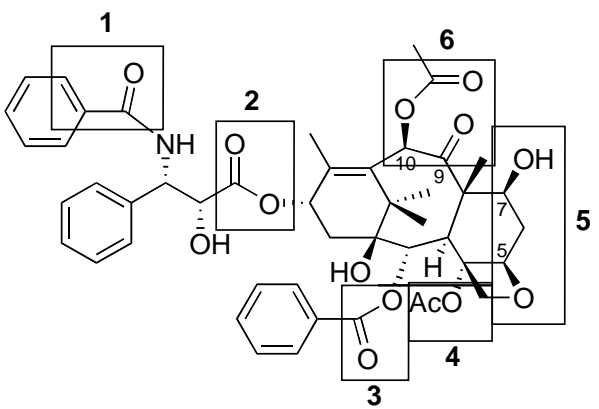

Group $1 \mathrm{Aa}(1.3)$ weak Group 2 AA (1.3) Group 3 AA (1.3) Group 4 AA (1.3) Group 5 AA (1.5) Group 6 AAA (1.4.6)

Figure 2. Analysis of paclitaxel for type I (1.3 and 1.5) and type II (1.4.6) interaction sites with Pgp.

10-Deacetoxypaclitaxel was prepared in one step via samarium diiodide-mediated deoxygenation. ${ }^{16,17}$ Treatment of paclitaxel (1) with $\mathrm{SmI}_{2}$ and acetic acid provided 10deacetoxypaclitaxel (3) in 91\% yield (Scheme 1).

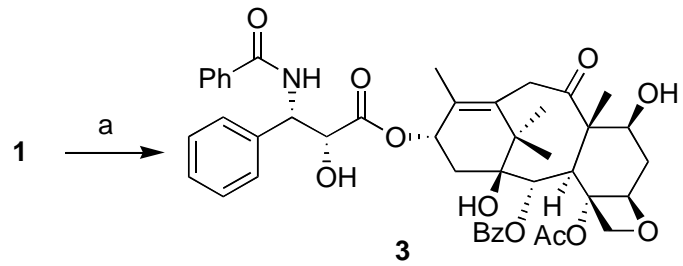

Scheme 1. a) $\mathrm{SmI}_{2}, \mathrm{AcOH}(91 \%)$.

7-Deoxypaclitaxel was prepared, employing the Barton deoxygenation reaction, as previously described by the Kingston group (Scheme 2). ${ }^{18}$ Treatment of paclitaxel (1) with tert-butyldimethylsilyl chloride, imidazole and 4(dimethylamino)pyridine furnished 2'-(tertbutyldimethylsilyl)paclitaxel (4) in 85\% yield. Compound 4 was treated with 2.2 equiv of sodium hydride in dry THF, then excess carbon disulfide and iodomethane to provided 5 in $65 \%$ yield. Treatment of $\mathbf{5}$ with tributyltin hydride and AIBN in toluene at $80{ }^{\circ} \mathrm{C}$, followed by deprotection of 2'-(tert-butyldimethylsilyl) yielded 7deoxypaclitaxel (6) in $48 \%$ from 5.

In the course of these studies, we also developed an efficient method to convert paclitaxel into 10-deacetoxy-7deoxypaclitaxel (7, Scheme 2). Treatment of 7deoxypaclitaxel (6) with $\mathrm{SmI}_{2}$ in the presence of $\mathrm{AcOH}$ furnished 7 in $82 \%$ yield. This method is superior to one reported earlier for the synthesis of $\mathbf{7}$, which produced a low overall yield (5\%). ${ }^{19}$ 

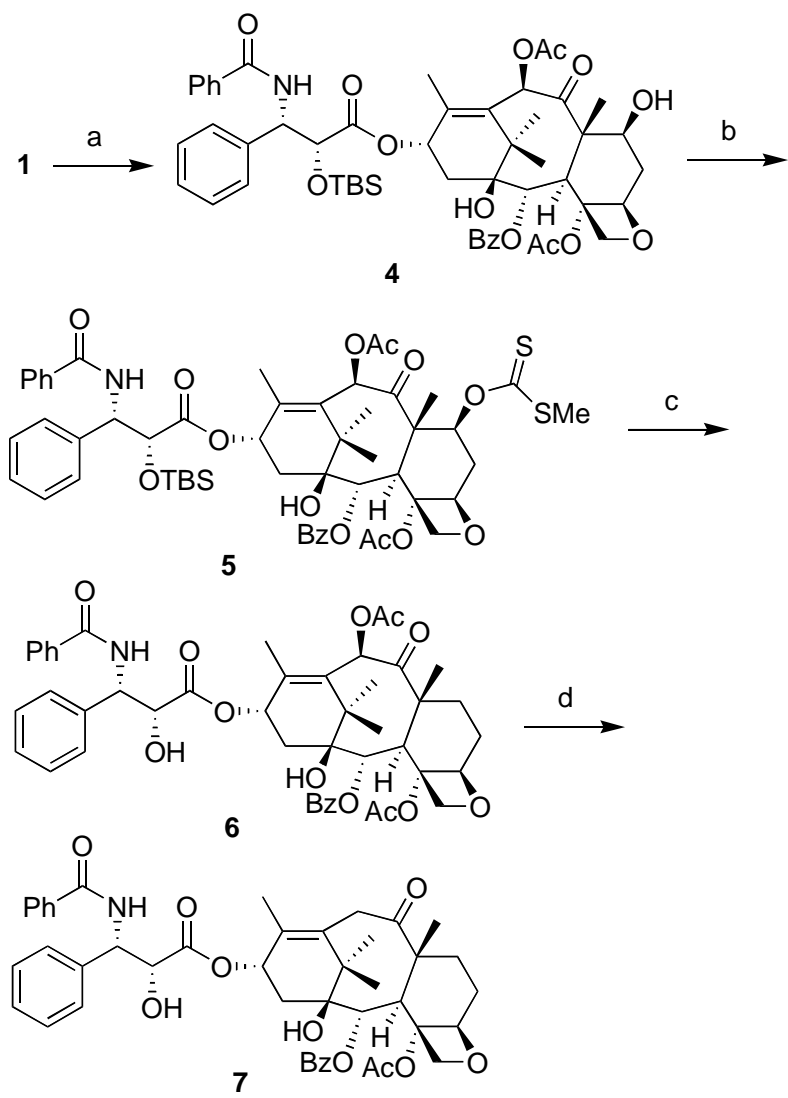

Scheme 2. a) TBSCl, imidazole, DMAP, DCM (85\%); b) NaH, $\mathrm{CS}_{2}$, MeI, THF (65\%); c) AIBN, Bu 3 SnH, PhH; then HF-Py, Py (48\% overall); d) $\mathrm{SmI}_{2}, \mathrm{AcOH}(82 \%)$.

Table 1. Biological Evaluation of Deoxypaclitaxel Analogues in a Tubulin Assembly Assay and for Antiproliferative Activity Against MCF7 and NCI/ADRRES Cell Lines. ${ }^{14}$

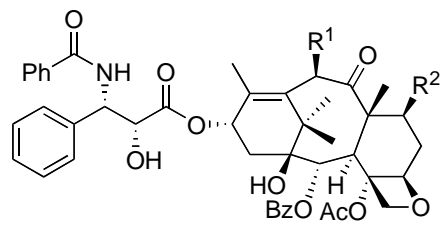

\begin{tabular}{|c|c|c|c|c|c|}
\hline Cmpd. $^{21}$ & $\mathrm{R}^{1}$ & $\mathrm{R}^{2}$ & $\mathrm{MT}^{\mathrm{a}}$ & $\mathrm{MCF}^{\mathrm{b}}$ & $\begin{array}{c}\text { NCI/ } \\
\text { ADR- } \\
\text { RES }^{\mathrm{c}}\end{array}$ \\
\hline $\mathbf{3}$ & $\mathrm{H}$ & $\mathrm{OH}$ & 2.2 & 0.87 & 0.79 \\
\hline $\mathbf{6}$ & $\mathrm{OAc}$ & $\mathrm{H}$ & 1.4 & 30.0 & 1.0 \\
\hline $\mathbf{7}$ & $\mathrm{H}$ & $\mathrm{H}$ & 2.0 & 9.0 & 0.21 \\
\hline
\end{tabular}

${ }^{\mathrm{a}}$ Microtubule assembly $\mathrm{ED}_{50} / \mathrm{ED}_{50}$ (Paclitaxel);

${ }^{\mathrm{b}} \mathrm{MCF} \mathrm{ED} \mathrm{D}_{50} / \mathrm{ED}_{50}$ (Paclitaxel);

${ }^{\mathrm{C}} \mathrm{NCI} / \mathrm{ADR}-\mathrm{RES}^{22} \mathrm{ED}_{50} / \mathrm{ED}_{50 \text { (Paclitaxel). }}$.

The three deoxygenated analogues 3, 6 and $\mathbf{7}$ were tested in a tubulin assembly assay and as inhibitors of proliferation against the MCF7 and NCI/ADR-RES breast cancer lines (Table 1). ${ }^{14}$ In the tubulin assembly assay analogue 6 was just slightly less active than paclitaxel, while 3 and $\mathbf{7}$ were about half as active as paclitaxel. Compound 3 had activity similar to paclitaxel against MCF7 proliferation but $\mathbf{6}$ and $\mathbf{7}$ had significantly reduced activity. Differences between the three analogues and paclitaxel against the resistant cell line NCI/ADR-RES were minimal. In a previous report it was found that $\mathbf{3}$ and 6 had essentially the same cytotoxicity as paclitaxel against HCT 116 cells while 7 was slightly less active. ${ }^{19,20}$

We assessed the analogues for rhodamine 123 uptake into bovine brain microvessel endothelial cells (BMECs). ${ }^{8}$ The intracellular concentration of rhodamine 123, itself a substrate for Pgp, is enhanced by compounds that compete for binding with Pgp in BMECs. Analogues 3, 6 and 7 were compared to paclitaxel at two concentrations and to cyclosporin A, as positive controls (Fig. 3). All compounds increased the level of rhodamine 123 uptake indicating that they interact with Pgp. At $5 \mu \mathrm{M}$, compounds $\mathbf{3}$ and $\mathbf{7}$ interacted less than paclitaxel and $\mathbf{6}$.

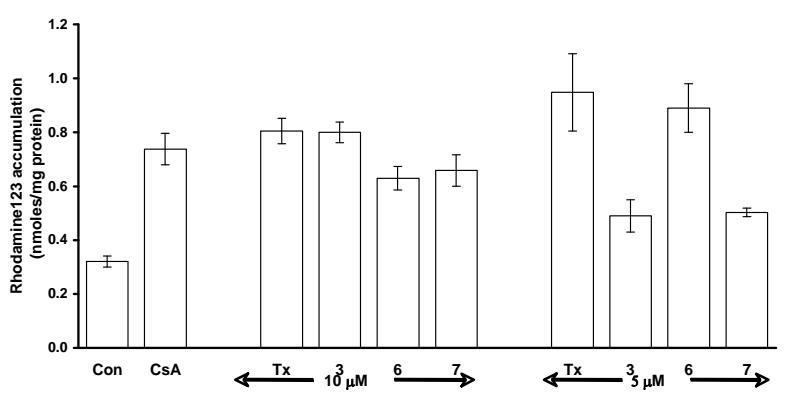

Figure 3. Rhodamine $123(5 \mu \mathrm{M})$ uptake into BMECs alone (Con = control) and in the presence of cyclosporin A (CsA) at $5 \mu \mathrm{M}$, and paclitaxel (Tx) and paclitaxel analogues 3, 6, and 7 at $10 \mu \mathrm{M}$ and $5 \mu \mathrm{M}{ }^{8}$

The lack of large differences between paclitaxel, 3, 6, and 7 as cytotoxic agents against NCI/ADR-RES cells indicate that removal of the group 5 and $\mathbf{6}$ (type II) recognition elements in paclitaxel did not reduce interactions between the paclitaxel analogues and Pgp in the MDR cancer cell line. Apparently, the interactions of the remaining group 1-4 recognition elements of the paclitaxel analogues 3, 6, and 7 with Pgp are sufficient enough for effective binding to cause efflux from MDR cancer cells.

The effect in BMECs is concentration dependent. Paclitaxel and the three analogues increased rhodamine 123 uptake into BMECs at $10 \mu \mathrm{M}$. However, at $5 \mu \mathrm{M}$, compounds 3 and 7, which both lack the C10 acetoxy group, had reduced uptake of rhodamine 123 in comparison to paclitaxel and compound $\mathbf{6}$, which lacks the C7 hydroxyl group but carries the C10 acetoxy group. The results demonstrate the importance of the group 6 recognition element for paclitaxel interaction with Pgp in BMECs. Compounds $\mathbf{3}$ and $\mathbf{7}$ are nevertheless substrates for Pgp because uptake of rhodamine 123 is increased in comparison to the rhodamine 123 control. As was the case 
with the MDR cancer cell line, the group 1-4 recognition elements are sufficient to increase rhodamine 123 uptake in comparison to the control. Overall, our original hypothesis, that removal of Pgp recognition elements could decrease the strength for Pgp binding, was verified, because rhodamine 123 uptake was clearly reduced for compounds $\mathbf{3}$ and $\mathbf{7}$ in BMEC's.

Acknowledgments: The authors wish to thank the National Cancer Institute for financial support of this research (NIH CA82801), and Tapestry Pharmaceuticals (Boulder, $\mathrm{CO}$ ) for a generous gift of paclitaxel.

\section{References and Notes:}

1. Wani, M. C.; Taylor, H. L.; Wall, M. E.; Coggon, P.; McPhail, A. T. J. Am. Chem. Soc. 1971, 93, 2325.

2. For review: Zhou, J.; Giannakakou, P. Curr. Med. Chem. - Anticancer Agents 2005, 5, 65.

3. $\quad$ Spencer, C. M.; Faulds, D. Drugs 1994, 48, 794.

4. $\quad$ Schinkel, A. H.; Smit, J. J.; van Tellingen, O.; Beijnen, J. H.; Wagenaar, E.; van Deemter, L.; Mol, C. A.; van der Valk, M. A.; RobanusMaandag, E. C.; te Riele, H. P. Cell 1994, 77, 491.

5. Schinkel, A. H.; Wagenaar, E.; Mol, C. A.; van Deemter, L. J. Clin. Invest. 1996, 97, 2517.

6. $\quad$ Sparreboom, A.; van Asperen, J.; Mayer, U.; Schinkel, A. H.; Smit, J. W.; Meijer, D. K.; Borst, P.; Nooijen, W. J.; Beijnen, J. H.; van Tellingen, O. Proc. Natl. Acad. Sci. U.S.A. 1997, 94, 2031.

7. Brouty-Boye, D.; Kolonias, D.; Wu, C. J.; Savaraj, N.; Lampidis, T. J. Cancer Res. 1995, 55, 1633.

8. $\quad$ Rice, A.; Liu, Y.; Michaelis, M. L.; Himes, R. H.; Georg, G. I.; Audus, K. J. Med. Chem. 2005, 48, 832.

9. $\quad$ Seelig, A. Eur. J. Biochem. 1998, 251, 252.

10. Seelig, A.; Li Blatter, X.; Wohnsland, F. Int. J. Clin. Pharmacol. Ther. 2000, 38, 111.

11. For review: Seelig, A.; Landwojtowicz, W.; Fisher, H.; Blatter, X. L. Methods and Principles in Medicinal Chemistry 2003, 18, 461.

12. For review: Georg, G. I.; Boge, T. C.; Cheruvallath, Z. S.; Clowers, J. S.; Harriman, G. C. B.; Hepperle, M.; Park, H. In Taxol ${ }^{\circledR}$ Science and Applications; Suffness, M., Ed.; CRC: Boca Raton, FL, 1995, 317.

13. Ojima, I.; Slater, J. C.; Michaud, E.; Kuduk, S. D.; Bounaud, P.-Y.; Vrignaud, P.; Bissery, M. C.; Veith, J. M.; Pera, P.; Bernacki, R. J. J. Med. Chem. 1996, 39, 3889.

14. Liu, Y.; Boge, T. C.; Victory, S.; Ali, S. M.; Zygmunt, J.; Georg, G. I.; Marquez, R. T.; Himes, R. H. Combi. Chem. High Through. Screen. 2002, 5, 39.
15. For review: Becker, T.; Mahboobi, S. Drugs Future 2003, 28, 767.

16. Georg, G. I.; Cheruvallath, Z. S. J. Org. Chem. 1994, 59, 4015.

17. Holton, R. A.; Somoza, C.; Chai, K. B. Tetrahedron Lett. 1994, 35, 1665.

18. Chaudhary, A. G.; Rimoldi, J. M.; Kingston, D. G. I. J. Org. Chem. 1993, 58, 3798.

19. Chen, S. H.; Huang, S.; Kant, J.; Fairchild, C.; Wei, J.; Farina, V. J. Org. Chem. 1993, 58, 5028.

20. Chen, S. H.; Fairchild, C.; Mamber, S. W.; Farina, V. J. Org. Chem. 1993, 58, 2927.

21. All compounds showed spectroscopic properties in agreement with their structures.

22. This cell line has been renamed NCI/ADR-RES as DNA fingerprinting has shown it is not derived from the MCF7 cell line: Scudiero, D. A.; Monks, A.; Sausville, E. A. J. Natl. Cancer Inst. 1998, 90, 862 . 